\title{
JUSTINIANO I, LEGISLADOR
}

\author{
Paulo Roberto Tellechea Sanchotene ${ }^{1}$
}

\begin{abstract}
RESUMO: O presente artigo apresenta a obra jurídica de Justiniano I, o Corpus Iuris Civile, em seu contexto histórico. Busca analisar os fundamentos e significados dessa legislação e os motivos pelos quais permanece importante atualmente.

PALA VRAS-CHAVE: Direito. His tória do Direito. Codificação. Corpus Iuris Civile. Justiniano I.
\end{abstract}

\section{JUSTINIAN I, LAWMAKER}

ABSTRACT: The present article shows Justinian I, the Corpus Iuris Civile, in its historical context. It attempt to analyze the foundations and meanings of this legislation and the reason which makes it still important today.

KEY WORDS: Law. History of Law. Codification. Corpus Iuris Civile. Justinian I.

\section{INTRODUÇÃO}

O presente trabalho pretende mostrar a obra jurídica do imperador bizantino Justiniano I dentro do seu contexto histórico. Tratar-se-á das mudanças ocorridas em Roma com o fim da República e o começo do Império, a divisão do Império em suas partes ocidental e oriental, a adoção do Cristianismo como religião oficial e a mudança da capital para Bizâncio (Constantinopla) com suas conseqüências para e no Direito. Apresentar-se-á Justiniano, apontando como ele compreendia o Império Romano e como ele via o papel do Direito nessa sociedade, mostrando seu projeto para consolidação e desenvolvimento do direito romano. Objetiva-se, com isso, resgatar um período importante da História, buscando aprender com essa experiência e procurar o que esses fatos teriam a ensinar-nos à luz dos problemas atuais.

\section{CONTEXTO HISTÓRICO}

Não se pode compreender a obra legislativa de Justiniano e a importância do Direito para ele e para o Império Bizantino sem conhecer os fatos que levaram a Constantino criar a "Nova Roma" no lugar da antiga cidade grega de Bizâncio, e as transformações no Império Romano de aí decorrentes. Tais temas serão tratados nesta primeira parte: primeiramente, com os fatos que levaram a constituição do Império, sua

\footnotetext{
${ }^{1}$ Advogado, mestrando em Dire ito pela UFRGS.
} 
posterior divisão nas partes ocidental e oriental, e a consolidação de Bizâncio como capital do Leste; posteriormente, das peculiaridades do Império Bizantino, sua autocompreensão, e sua organização política e social até a ascensão de Justiniano ao poder.

\section{I.1 A Divisão do Império e a Capital do Oriente}

Com a expansão dos seus domínios, a forma Republicana de Roma começava a dar sinais de insustentabilidade. A República mostrava-se débil para resolver os novos problemas que surgiam e as situações de crise passaram a ser regra; não mais, exceção. As províncias necessitavam de um maior controle, ao mesmo tempo em que os cidadãos romanos exigiam uma maior atenção por parte das autoridades. Havia um clamor por mudanças $^{2}$. A política expansionista havia chegado a um ponto em que não era mais possível a Roma retornar ao que antes era. O destino da República estava selado; sua existência chegara definitivamente ao fim. Contudo, essa derrocada seria lenta e gradual, com momentos de retrocesso. Júlio César foi o primeiro a utilizar-se de fórmulas republicanas contra a República, acabando com o limite de eleições de um ditador, mas também foi o primeiro a sofrer as consequiências do ímpeto em alterar o que estava consolidado a séculos: foi assassinado, em 44 a.C., por seus oposicionistas no Senado ${ }^{3}$. Coube a Otávio Augusto - governou entre 30 e 14 a.C.- descobrir a maneira de transformar Roma sem rupturas ${ }^{4}$, ao estabelecer -o que se atreve ora a chamar deum Império Republicano.

Tal iniciativa, todavia, era insustentável no longo prazo; e novas fórmulas necessitavam ser descobertas e estabelecidas: ${ }^{5}$ a mais importante delas, provavelmente, tendo sido a divisão administrativa do Império. Roma, ao contrário do que possa parecer, não era una. Um exemplo disso é que nos territórios a leste de Roma, o idioma universal era o grego e não, o latim. Tal fato se dá pela permissividade com que os romanos tratavam os povos conquistados ${ }^{6}$. Isso, por si, gerara uma divisão cultural que impedia um tratamento único por parte do governo de Roma. A solução encontrada por Diocleciano (imperador entre 284 e 305 d.C.), talvez inspirado na tradição diárquica da

\footnotetext{
2 Para maiores detalhes ver: BURNS, Edward MacNall. História da Civilização Ocidental. Porto Alegre: Globo, 1972. 2.ed. Vol I. p.219-225; e AQUINO, Rubim Santos Leão de et al. História das Sociedades: das comunidades primitivas às sociedades medievais. Rio de Janeiro: Ao Livro Técnico, 1980. p.234-242.

${ }^{3}$ AQUINO, Rubim Santos Leão de et al. Op. Cit.. pp.242-243.

${ }^{4}$ BURNS, Ed ward Mac Nall. Op. Cit. pp. 230-231.

${ }^{5}$ RUNCIMAN, Steven. A Ci vilização Bizantina. Rio de Janeiro: Zahar, 1961. p.12.

${ }^{6}$ Op. Cit. p. 14.
} 
República Romana, foi dividir o poder entre dois imperadores ${ }^{7}$ - ambos responsáveis pelo todo - mas com prioridade sobre uma das partes ${ }^{8}$. Foi o golpe que faltava para a derrocada de Roma como centro político do mundo.

Os romanos tinham como característica se deixar influenciar pelas culturas existentes nos territórios conquistados e, ao entrarem em contato com as civilizações orientais, não houve exceção. Os próprios gregos já se haviam embebido antes dessa influência com o fim das cidades-Estado e o surgimento do Império Macedônico ${ }^{9}$. Para os orientais, uma República é algo impensável, sendo a figura imperial preponderante e vital na organização de uma sociedade. As sociedades orientais organizavam-se a espelho de suas crenças religiosas e viam-se como reflexo direto da ordem transcendente; a ordem do $\operatorname{Cosmos}{ }^{10}$. Nesse aspecto, o Imperador é o elo entre a ordem terrestre e a celestial, do que recebe seu caráter divino ${ }^{11}$. Contudo, Roma nunca abdicou de suas próprias tradições, e ver na figura do Imperador - um homem - um ser divino era demasiado difícil para a racionalidade romana. Não à toa, no início do século VI, Diocleciano mudara-se para Nicomédia (era imperador do Oriente) e sua contraparte ocidental, Maximiano, foi governar em Milão ${ }^{12}$. Um império, mesmo o Império Romano, não poderia subsistir que no Oriente e não tardou para que a parte ocidental sucumbisse. Entre os anos de 476 e 800, o Ocidente romano permaneceu politicamente acéfalo $^{13}$ e, mesmo após a coroação de Carlos Magno, a capital jamais voltou a ser Roma ${ }^{14}$. A cidade imperial por excelência era definitivamente Constantinopla.

\section{I.2 O Império Bizantino}

Quando Constantino - após a adoção do Cristianismo - consegue unificar o Império, entendeu por bem construir uma nova capital. O lado oriental do Império

\footnotetext{
${ }^{7}$ AQUINO, Rubim Santos Leão de et al. Op. Cit. p. 255.

${ }^{8}$ KOSCHAKER, Pablo. Europa y el Derecho Romano. Madrid: RDP, 1955. p.26.

${ }^{9}$ ROTH, Karl. Historia del Imperio Bizanti no. Barcelona: Labor, 1943. pp.10-11.

${ }^{10}$ VOEGELIN, Eric. A Nova Ciência da Política. Brasília: UNB, 1982. 2.ed. p.50.

11 “Los teólogos establecen un paralelo, por un lado, entre la poliarquía de las naciones, divididas entre ellas por guerras continuas, y el politeísmo, concepción anárquica del universo, y por otro, entre la monarquía imperial y el dogma de la unidad divina: un solo Dios en el cielo, un solo emperador en la tierra." BRÉHIER, Louis. Las Instituciones del Imperio Bizantino. México: UTEHA, 1956. pp. 3-4.

12 RUNCIMAN, Steven. Op. Cit. p.11.

13 JOHNSON, Paul. Historia del Cristianismo. Buenos Aires: Vergara, 2004. p. 173.

${ }^{14}$ A capital política, a partir de Carlos Magno, nunca mais foi Roma: “... Carlos Magno fue... oriundo de Austrasia, país poco romanizado... a diferencia de los morovingios no gobernó su reino desde Paris, Soisson u Orleans, sino desde su misma patria, desde Ilgenheim, Aquisgrán o Nymwegen..." KOSCHAKER, Pablo. Op. Cit. p.56.
} 
necessitava de maiores cuidados em razão da perigosa vizinhança, bem como sua localização estratégica colocava o Império de frente para o mundo. Certamente não foi a conversão de Constantino ao Cristianismo que o fez estabelecer a capital do Oriente em Bizâncio, rebatizando-a de "Nova Roma" ou Constantinopla, mas, sim, sua posição estratégica e entreposto entre o Ocidente e a Ásia. Todos os caminhos, de fato, não levavam a Roma, mas a Bizâncio; onde comerciantes persas, chineses e indianos encontravam-se com os africanos e europeus. Da naturalmente guarnecida Bizâncio, as tropas romanas poderiam deslocar-se para todo o mundo conhecido ${ }^{15}$. Era apenas questão de tempo para que Constantinopla se tornasse a cidade mais importante do Império; levou mais de século, mas finalmente o Oriente se impôs como o local natural para a sequiência da tradição romana ${ }^{16}$.

Seguramente, não foi a conversão que motivou a mudança de capital, mas o estabelecimento do elemento cristão ao Império, de uma só vez, estabeleceu as raízes do que se convencionou de civilização ocidental - algo que não diz respeito ao presente trabalho - e transformou o Império do Oriente em algo único na História da humanidade. Afinal, como se viu, a sociedade bizantina foi construída sobre quatro alicerces: ela era tradicionalmente romana; culturalmente grega; politicamente oriental; e religiosamente cristã. Era parcialmente todas, mas integralmente nenhuma, pois cada um de seus elementos influenciou a compreensão do outro. Como Roma, em Constantinopla havia o povo e o Senado, mas com conotações bem distintas daquelas da antiga capital. Sua força política era meramente residual ${ }^{17}$, pois a figura do Imperador, por força da influência oriental, centralizava a política, o direito e a religião. Todavia, inexistia a figura divina do Monarca como ocorria na China e na Pérsia, além disso, o Imperador fazia parte da Igreja, mas não era "a" Igreja; não se confundia com ela ${ }^{18}$. A nomeação do imperador bizantino passava pela aprovação do povo, do Senado e do Exército, mas, normalmente tratava-se apenas de uma ratificação ${ }^{19}$.

A vida social girava em torno do Hipódromo, em que os diferentes grupos sociais organizados disputavam corridas de cavalos. Os grupos políticos foram

\footnotetext{
${ }_{16}^{15}$ BRÉHIER, Louis. Vida y Muerte de Bizancio. México: UTEHA, 1956. p.1-6.

${ }^{16}$ RUNCIMAN, Steven. Op. Cit. p.24-31.

17 “... there was no real assembly or parliament to focus issues: the Senate (or syncletos), a body compost of past and present officials, was in normal times confined to the function of electing certain officials... There were indeed quasi-political groups, of the nature of factions rather then parties, which went by the name of 'demes'...; but these groups were confined to the city of Constantinople..." BARKER, ERNEST (org.). Social and Political Thought in B yzantium. Oxford: Clarendon, 1957. p.5.

${ }^{18}$ Op. Cit. p.6-8.

${ }^{19}$ RUNCIMAN, Steven. Op. Cit. p.53.
} 
distinguidos pelas cores de seus carros: os azuis; os verdes; os vermelhos; e os brancos; sendo os dois primeiros os mais importantes. Tais grupos também formavam milícias armadas, o que sempre deixava tenso o clima na Bizâncio do início do Império ${ }^{20}$. A Guerra Civil era algo sempre iminente. Ela eclodiu justamente durante o império de Justiniano, em 532. Por pouco, não houve um golpe de Estado. A reação implacável do imperador, apoiado por sua esposa Teodora, restabeleceu a ordem sobre os corpos de mais de 30.000 revolucionários $^{21}$. Após esse evento, Justiniano e Teodora passaram a equilibrar as ações entre os azuis (protegidos do imperador) e os verdes (protegidos da imperatriz), trazendo paz interna à Constantinopla ${ }^{22}$. Mas não estava na sua capacidade política, nem nos seus feitos militares ${ }^{23}$ e $\operatorname{arquitetônicos}^{24}$, tampouco nas suas realizações teológicas a maior obra de Justiniano; foi pelo Direito que ele entrou efetivamente para a História.

\section{JUSTINIANO E O DIREITO}

Nesta segunda parte, explicitar-se-á o desenvolvimento do Direito Romano e o papel de Justiniano para a consolidação e perpetuação desse Direito. Na segunda parte, faz-se um relato de como foi o trabalho de Justiniano no campo jurídico, através do exemplo de sua principal obra: o Corpus Iuris Civile.

\section{II.1 O Direito Romano}

Nas sociedades humanas mais simples, tudo o que se conhece está intimamente ligado à natureza e a algo sobre esta, do que o único que sabe é que se desconhece. Tal desconhecimento é preenchido por mitos cosmológicos, que "explicam" o mundo e o homem ${ }^{25}$. O homem se vê, nessas sociedades, como algo integrante e não-independente do mundo: ele tanto faz parte do mundo como o mundo faz parte dele ${ }^{26}$. Essa visão de mundo tem consequiências diretas ao Direito que regula essa sociedade - afinal, o

\footnotetext{
${ }^{20}$ BAILLY, Auguste. Byzance. Paris: Arthéme Fayard, 1957. p. 52-56.

${ }^{21}$ ROTH, Karl. Op. Cit. p.22-23.

${ }^{22}$ BAILLY, Auguste. Op. Cit. p.81.

${ }^{23}$ BRÉHIER, Louis. Vida y Muerte de Bizancio. Op. Cit. p.21-24.

${ }^{24}$ BAILLY, Auguste. Op. Cit. 92-94

${ }^{25}$ VOEGELIN, Eric. Op. Cit. p.53.

${ }^{26}$ GROSSI, Paulo. E Orden Jurídico Medieval . Madrid: Marcial Pons, 1996. p. 85.
} 
Direito tem sua função no ordenamento concreto da sociedade ${ }^{27}$. Este, pois, nessas sociedades, tende a ser ritualístico, formular e religioso ${ }^{28}$. Como o homem está intimamente ligado ao Universo, seus atos encontram correspondência na natureza, ao mesmo tempo em que são influenciados por ela. É normal utilizar-se de fatos naturais como elementos integrantes do Direito: o tempo, os animais, as plantas, as águas, o fogo, o corpo, etc. ${ }^{29}$

O Direito Romano não escapou dessa influência, seja nos seus primórdios ${ }^{30}$; seja em momentos de crise, quando em contato com o Direito bárbaro, após a queda do Império Romano do Ocidente ${ }^{31}$. Entretanto, na medida em que a sociedade romana foi tendo outra compreensão de si mesma e de seu lugar no mundo, o Direito Romano modificou-se, afastando os elementos místicos e supersticiosos. Quando o homem passa a compreender-se como parte autônoma da natureza, presente, mas não integrante, o seu Direito também muda para expressar essa nova Ordem, como ocorrera nas pólis gregas no final do período helenístico (pela Filosofia) e em Israel (pela Revelação) ${ }^{32}$. Mas, como se viu, a sociedade romana seguia redescobrindo-se e a conversão do Imperador Constantino acrescentou-lhe um novo elemento: o cristianismo. Todavia, a mudança de capital e as graves crises internas poderiam sepultar o Direito Romano como se conhecia não fosse o trabalho restaurador de Justiniano ${ }^{33}$. Assim, se Constantino é o responsável pela absorção do cristianismo pelo Império Romano, Justiniano é, de fato, quem definiu qual o grau de influência que essa exerceria no Direito, alterando de maneira definitiva a compreensão romana do que é o Direito ${ }^{34}$.

Ao consolidar o Direito Romano como o vigente no Império, Justiniano transformou a sociedade bizantina -e conseqüentemente, o seu Direito- em algo único,

\footnotetext{
${ }^{27}$ VOEGELIN, Eric. The Nature of The Law: and related legal writings. Baton Rouge: LSU, 1991. p. 67-68.

28 BERMAN, Harold J. La Formación de la Tradición Jurídica de Occidente. México: FCE, 1996. p. $62-72$

${ }^{29}$ GROSSI, Paolo. Op. Cit. p.84-92.

${ }^{30}$ Co mo bem exemp lificado por Antonio Guarino, quando trata do Direito estab elecido em Ro ma em sua época tribal. Para mais, ver: GUARINO, Antonio. L'Ordinamento Giuridico Romano. Napoli: Eugênio Novene, 1956. 2. ed. 301 p; principalmente o capítulo I.

31 "De hecho, durante todo el primer medievo ha permanecido un filón jurídico de algun modo romanoelemental, rudimentario, alejadísimo de los refinados cultismos del Digesto -, sobre todo em alguns territorios, al tiempo que la Iglesia se habia nutrido siempre de Derecho romano ..." GROSSI, Paolo. Op. Cit. p. 162.

32 VOEGELIN, Eric. The Nature of The Law. Op. Cit. p. 68.

${ }^{33}$ Como se verá adiante, anteriormente a Justiniano, houve outras obras de compilação legislativa em Constantinopla; todavia nenhuma com a abrangência e com o foco na raiz romana do Direito do Corpus Iuris Civile.

${ }^{34}$ O Império Bizantino, frise-se, é romano. Os bizantinos, inclusive, se auto-denominavam romanoi; isto é, romanos.
} 
diferente a tudo o que o mundo conhecia anteriormente. É tentador falar em evolução, mas isso pareceria darwinista em demasia ${ }^{35}$. O melhor termo para exemplificar as mudanças seria "sobreposição". Aos modelos anteriores foi sobreposta essa nova Ordem do Império, porém permanecendo características das anteriores. Justiniano, por exemplo, congregou os elementos da razão, presentes na filosofia grega e romana, e da Revelação, herdados do Judaísmo pelo Cristianismo, como fontes autoritativas de Ordem. A Ordem Imperial, portanto, baseava-se em três fontes: o Poder, a Razão e a Revelação ${ }^{36}$. Por essa razão, os legisladores por mais poder que tivessem não agiam como ditadores de um regime totalitário moderno. O fato é que esses estavam todos limitados por fontes externas de autoridade. Como bem resumiu o Imperador Leão III (717-741), o poder legislativo imperial encontrava limites nas Sagradas Escrituras, nas decisões dos Sínodos e Conselhos, e no Direito Romano ${ }^{37}$. O Imperador que não observasse tais normas não estaria legislando, mas descumprindo a Lei. Essa compreensão do Direito foi totalmente perdida na modernidade, principalmente após as codificações, em que a principal fonte autoritativa do Direito passou a ser o Poder e apenas o Poder, fosse o poder do príncipe ou do povo. O Direito Moderno perdeu totalmente suas raízes românicas, sendo representante de uma Ordem distinta daquela estabelecida no Império Romano e no Ocidente. ${ }^{38}$ Hoje, o Direito encontra-se em crise, situação com que Justiniano se deparou ao se tornar Imperador em $527 .{ }^{39}$

\section{II.2 O Corpus Iuris Civile}

Assim que foi coroado Imperador, Justiniano sentiu a necessidade de trazer ordem a uma sociedade em ebulição. Seu primeiro ato foi reorganizar o Direito Romano, seguindo os passos do imperador Teodósio $(379-395)^{40}$. Contudo, Justiniano resolveu ir além de seu antecessor, que apenas organizara as leis novas promulgadas

\footnotetext{
${ }^{35}$ Não se trata de evolução porque não há uma seqüência temporal entre os diversos tipos de ordenação social, em que o novo é superior ao velho. Tais ordenações, de fato, co-existem no tempo. Para mais informações, ver: VOEGELIN, Eric. A Nova Ciência da Política. Brasília: UNB, 1982. 2. ed. 148 p; principalmente, o capítulo II.

${ }^{36}$ Is so refletiu-se também no Ocidente. VOEGELIN, Eric. The Nature of The Law. Op. Cit. p.68.

${ }^{37}$ KOPPANY SANTA PINTER, J. J. Roman By zantine Law: anatomy of the creation of byzantine law. In: http://www.new-byzantiu m.org/orderof.html. Acessado em 28 de novembro de 2008.

38 VOEGELIN, Eric. The Nature of The Law. Op. Cit. p.68-69.

39 Tal crise não é exclusiva do Direito, pelo contrário. A crise é da sociedade moderna como um todo, sendo o problema do Direito um sintoma. Contudo, tal como já apontara Voegelin em "A Nova Ciên cia da Política" (1952), esse problema recém está começando e o final é incerto. Tal afirmação, crê -se, ainda é válida.

${ }^{40}$ RUNCIMAN, Steven. Op. Cit. p.62
} 
pelo Imperador desde Constantino I. Justiniano via-se como imperador romano e sentia a necessidade de que Constantinopla respeitasse e mantivesse o vínculo com sua História. E tal vínculo só poderia ocorrer através do Direito, a principal herança recebida de Roma. Justiniano acreditava que o Direito era uma arma tão preciosa para o governo interno quanto a força militar era para a defesa e conquista; reconhecia a necessidade, para que um governo central funcionasse efetivamente, de um direito organizado, estável e único. No entanto, o Direito Romano estava perdido em meio a fontes difusas, dispersas e contraditórias. Era impossível ao Imperador legis lar sem conhecer o Direito, e para conhecê-lo era preciso organizá-lo. ${ }^{41}$ Assim, Justiniano focou-se na tarefa de organizar o direito bizantino - e, por consequiência, romano -, em dimensão não apenas legislativa, mas também doutrinária e didática. O jus-historiador italiano Antonio Guarino explica as dimensões de tal obra jurídica em seu livro “Ordinamento Giuridico Romano", onde trata do desenvolvimento do Direito em Roma desde as tribos até o Corpus Iuris Civile de Justiniano. Esse livro será a base do que está descrito a seguir.

O Corpus Iuris Civile não foi realizado de maneira unificada. Inclusive, a teoria aceita hodiernamente é que ela resulta, de fato, de um processo. A obra foi sendo amadurecida com o passar das etapas. Justiniano provavelmente não tinha a menor idéia do que iria concretizar quando ordenou o início dos trabalhos. A obra, ao final, é o resultado de quatro etapas distintas, uma correspondente a cada parte, cada parte autônoma em si, mas vinculada aos demais pela totalidade do projeto: o desejo do imperador em restaurar uma romanidade praticamente perdida após mais de dois séculos de decadência. Pouco depois de assumir o cargo de Imperador, Justiniano decretou a necessidade de se compilar um novo Código, tendo como base as obras de Gregório, Hermógeno - do is códigos privados-e do imperador Teodósio, bem como na legis lação posterior à época teodosiana. O objetivo era estabelecer as leis gerais do Império, afastando as leis não mais em vigor -o que simplificava o trabalho dos aplicadores do Direito. Para a realização da tarefa foi nomeada uma comissão que organizou o direito vigente no que se chamou de Codex Instinianus. O código que se conhece é a sua segunda edição, promulgada em 534, provavelmente mais completa que a primeira, de 529. O Codex repetita praelectiones, nome oficial da segunda edição, foi dividido em doze livros, sendo que: o primeiro tratava das fontes do direito, de argumentos de direito

\footnotetext{
${ }^{41}$ BAILLY, Auguste. Op. Cit. p.94
} 
público e direito eclesiástico; o direito privado era tratado dos livros segundo a oitavo; o livro nono trazia a legislação penal; e os últimos três regulavamo direito público.

Apenas da conclusão do primeiro Codex é que Justiniano teria percebido a necessidade da realização de uma nova obra jurídica. Além da legislação, era preciso algo mais; algo que desse compreensão ao próprio Código. Se a primeira etapa tratava da legislação, a segunda, apesar de ter força de lei, apontava de fato seu espírito: o Direito e a Justiça. A segunda comissão organizou, no que ficou conhecido como Digesto seu Pandectce (533), o iura, ou seja, o antigo Direito Romano traduzido na doutrina e nas decisões dos antigos jurisconsultos, principalmente Ulpiano, Paulo, Papiniano, Gaio e Modestino. O Digesto era composto de cinqüenta livros, agrupados pelo próprio Justiniano por matéria em sete partes: (I) livros primeiro a quarto, sobre os princípios gerais de direito e sobre a jurisdição; (II) livros quinto a undécimo, sobre a doutrina geral da ação, a proteção jurídica da propriedade e sobre outros direitos reais; (III) livros duodécimo a décimo nono, sobre obrigações e contratos; (IV) livros vigésimo a vigésimo sétimo, sobre outros institutos das obrigações e sobre relações jurídicas de família; (V) livros vigésimo oitavo a trigésimo sexto, sobre heranças, legados e fideicomissos; (VI) livros trigésimo sétimo a quadragésimo quarto, sobre sucessão pretoriana, múltiplos institutos sobre direitos reais, posse e obrigações; e, por fim, (VII) os últimos seis livros, sobre stipulatio e institutos conexos, direito penal, apellatio e direito municipal.

A terceira parte, apesar de oficialmente também ter peso de lei, tinha como principal objetivo substituir as Institutiones de Gaio nas escolas de Direito; seus fins eram acadêmicos. A comissão responsável organizou material, baseado principalmente no primeiro Codex, no Digesto e na própria Institutiones de Gaio. O livro recebeu o nome de Institutiones Iustiniani Augusti, ou Instituta e foi promulgado em 533. A obra dividia-se em quarto livros: (I) o primeiro tratava das pessoas; (II) o segundo, das coisas; (III) o terceiro, das sucessões e das obrigações; e, por fim, (IV) o quarto tratava das obrigações decorrentes de delito, em que falava dos atos ilícitos e das penas deles decorrentes. A partir desse trabalho, Justiniano ordenou a reforma do ensino jurídico no Império, sendo que nos primeiros três anos se estudariam as Instituições; o Digesto seria estudado no terceiro e quarto anos; e o Código, no último (quinto) ano.

Com essas três partes estava concluído o alicerce legal e jurídico do Império. Mas, ao contrário das primeiras Codificações modernas, o objetivo de Justiniano nunca foi o de esgotar a matéria, mas o de estabelecer uma base para o desenvolvimento do 
Direito, o que ele faria através da quarta parte do seu trabalho: a elaboração de leis novas ou Novellae. Somente com a reunião num único corpo dos elementos esparsos (legislação, doutrina, jurisprudência) e com a adequação da antiga ciência jurídica a princípios rigorosos, seria permitido ao legislador exercer seu papel, confor me afirmou o próprio Justiniano na Sétima Novela: o de emendar, enriquecer e, até mesmo, onde fosse necessário, limitar a $\mathrm{le}^{42}$. A totalidade dessas quatro partes - Codex, Digesto, Instituta e Novella - formam o Corpus Iuris Civile.

\section{CONCLUSÃO}

Se a premissa aqui utilizada está correta, ou seja, de que é impossível compreender o Direito fora do seu contexto social, entender as reformas justinianas implicaria obrigatoriamente conhecer o Império Bizantino, suas raízes e influências. Pelo relatado anteriormente, constata-se que a auto-compreensão dos bizantinos como romanos foi vital para o restabelecimento do Direito Romano como autoridade no ordenamento daquela sociedade. Apesar de ter sofrido influências orientais, foi a presença dos espíritos romano e cristão, consolidadas na obra de Justiniano, que impediu Constantinopla - e posteriormente, o Ocidente- de voltar a ter um direito meramente mítico. O seu trabalho de restauração da Ordem romana combinado com os elementos novos herdados da conversão de Constantino serviu de alicerce às transformações sociais ocorridas no Ocidente e no Oriente europeu por mais de mil anos. Em meio ao caos e guerras, as reformas de Justiniano permitiram que o Direito exercesse o seu papel ordenador, e servisse de ponto-de-apoio e de segurança às pessoas. Além disso, o exemplo de Justiniano demonstra que há mais no Direito que normas puras, comportamentos ou vontade soberana; que o reduzem a uma de suas facetas. O Corpus Iuris Civile, ainda, mostra-se uma obra -apesar de alicerçada no passado, na tradição jurídica romana- aberta ao futuro, aos problemas bizantinos

\footnotetext{
${ }^{42}$ Justiniano, no Prólogo dessa novella, além de relatar a função do legislador, deixa claro que quem utiliza a lei para corromper seu espírito igualmente comete fraude e de mesmo grau de quem não respeita o exposto no texto: “... It has always been our aim to correct whatever was previously imperfect and perplexing, and to render the imperfect perfect. Since we have done that in all our legislation, we think we should also in connection with alienation of sacred property embrace all prior laws in one, adds what is lacking and leaves out what is superfluous. [...] It [lei promulgada anteriormente por Leão, a qual Justiniano reforma] was not able to meet the evil-mindedness of the future time. For some, the colonistic right having been invented - known neither to our laws nor to any one - to bring about an almost perpetual alientation commited no small fraud to our law..." tradução de Fred H. Blume, encontrada em: http://uwacadweb.uwyo.edu/blume\&justinian/novell-20/novel120.htm
} 
conforme esses foram se apresentando nos quase 900 anos de aplicação da legislação. Em nenhuma hipótese, Justiniano desenvolvera ou, até mesmo, tivera a intenção de criar um sistema perfeito e fechado, como os codificadores modernos. Por tais fatos, o trabalho como legislador de Justiniano tornou-se um marco na História da civilização ocidental; e seu exemplo, de como se agir em épocas de crise, seguirá eternamente válido.

\section{BIBLIOGR AFIA}

AQUINO, Rubim Santos Leão de et al. História das Sociedades: das comunidades primitivas às sociedades medievais. Rio de Janeiro: Ao Livro Técnico, 1980. 458 p.

BAILLY, Auguste. Byzance. Paris: Arthéme Fayard, 1957. 442 p.

BARKER, ERNEST (org.). Social and Political Thought in Byzantium. Oxford: Clarendon, 1957, 239 p.

BERMAN, Harold J. La Formación de la Tradición Jurpidica de Occidente. México: FCE, 1996. 674p.

BRÉHIER, Louis. Vida y Muerte de Bizancio. México: UTEHA, 1956. 537 p.

BRÉHIER, Louis. Las Instituciones del Imperio Bizantino. México: UTEHA, 1956. $567 \mathrm{p}$.

BURNS, Edward MacNall. História da Civilização Ocidental. Porto Alegre: Globo, 1972. 2.ed. Vol I. 581 p.

GROSSI, Paulo. El Orden Jurídico Medieval. Madrid: Marcial Pons, 1996. 256p.

GUARINO, Antonio. L'Ordinamento Giuridico Romano. Napoli: Eugênio Novene, 1956. 2. ed. 301 p.

JOHNSON, Paul. Historia del Cristianis mo. Buenos Aires: Vergara, 2004. 741 p. 
KOPPANY SANTA PINTER, J. J. Roman Byzantine Law: anatomy of the creation of byzantine law. In: http://www.new-byzantium.org/orderof.html. Acessado em 28 de no vembro de 2008 , às $13 \mathrm{~h} 30 \mathrm{~min}$.

KOSCHAKER, Pablo. Europa y el Derecho Romano. Madrid: RDP, 1955. 516 p.

ROTH, Karl. Historia del Imperio Bizantino. Barcelona: Labor, 1943. 184 p.

RUNCIMAN, Steven. A Civilização Bizantina. Rio de Janeiro: Zahar, 1961. 233 p.

VOEGELIN, Eric. The Nature of The Law: and related legal writings. Baton Rouge: LSU, 1991. 119p.

VOEGELIN, Eric. A Nova Ciência da Política. Brasília: UNB, 1982. 2. ed. 148 p. 